\title{
Responsabilidade civil do magistrado na concessão de medida cautelar ex officio.
}

\author{
Clayton Reis*
}

\begin{abstract}
Sumário: 1.Breves conceitos sobre medida cautelar; 2.Importância das medidas cautelares; 3.Atos e poder do juiz no processo; 4.Condições para concessões da medida cautelar; 5.Concessão da medida cautelar ex officio; 6.Dano decorrente da concessão da medida cautelar; 7.Responsabilidade civil do magistrado; 8.Conclusões.
\end{abstract}

\section{Breves conceitos sobre medida cautelar}

O processo cautelar, que pode ser preparatório ou incidente, conforme tenha lugar antes ou depois do processo principal, tem como escopo tutelar de forma imediata o interesse da parte. Todavia, é necessária a existência de fundado receio, de que o ato cause ao direito da parte lesão grave ou de difícil reparação.

A urgência, elemento marcante nesse procedimento, é um dos pressupostos necessários ao deferimento da medida pelo juiz.

Luiz Guilherme Marinoni, ${ }^{1}$ nesse particular, prescreve que "a tutela cautelar é espécie do gênero tutela urgente. Surge, com efeito, para eliminar uma situação de perigo que coloque em risco uma pretensão."

* Magistrado no Paraná, Professor da Universidade Estadual de Maringá, Diretor da Escola da Magistratura do Paraná, Mastrando em direito pela Universidade Federal do Paraná.

1 Luiz Guilherme Marinoni, Tutela Cautelar e Tutela Provisória, Revista dos Tribunais, 1992 , p. 59.

R. Fac. Direito, Curitiba, a.28, n.28, 1994/95, p.173-188 
São, na realidade, medidas de segurança, de garantia conforme expressão de Sérgio Sahione Fadel ${ }^{2}$ ou seja, medidas capazes de assegurar às partes a efetiva aplicação do direito.

Aliás, o mesmo autor, preleciona que, ${ }^{3}$ "conforme salienta Chiovenda (Instituições de Direito Processual Civil, vol. 1, pag. 274), a medida provisória corresponde à necessidade efetiva e atual de afastar 0 temor de um dano jurídico; se, pois, na realidade esse dano é ou não iminente, apurar-se-á na verificação definitiva. Fundado nela, poderá revogar-se, modificar-se "ou confirmar-se" o despacho na última hipótese, pode transformar-se em medida executiva (sequestro conservador que se converte em penhora)."

Para a concessão da medida cautelar basta a existência de razoável probalidade ou de fato que configure a existência de um risco iminente periculum in mora. ${ }^{4}$

Portanto, infere-se, "a prior", que estamos diante de uma situação de risco, onde a incerteza é o elemento marcante, que exige do executor da medida ponderável prudência, para não gerar dano maior do que aquele que se pretende eliminar.

Assim, o pressuposto da instantaneidade do direito é elemento central na medida cautelar, objetivando assegurar a imediata e eficaz prestação da tutela, sem o que, o processo perderia a sua instrumentalidade, tão decantada por Cândido Rangel Dinamarco. Por tais motivos, autoridades do escol de Antonio Carlos de Araujo Cintra, Ada Pellegrini Grinover e Cândido R. Dinamarco destacaram em sua obra ${ }^{5}$ que "a atividade cautelar foi preordenada para evitar que o dano oriundo da inobservância do direito

2 Sérgio Sahione Fadel, Código de Processo Civil Comentado, $4^{\mathrm{a}}$ ed., Rio de Janeiro, Forense, 1982, p. 649.

3 Sérgio Sahione Fadel, Código.... op. cit., p. 649.

4 Cândido Rangel Dinamarco, A Instrumentalidade do Processo, p. 260, nesse aspecto preleciona que, "toda atividade cautelar apoia-se, or destinação institucional, nas incertezas representadas pelo fumus boni juris, onde a razoável probabilidade ou mesmo a não exclusão dos fatos alegados basta para a concessão da medida jurisdicional."

5 Antonio Carlos de Araujo Cintra, Ada Pellegrini Grinover e Cândido Rangel Dinamarco, Teoria Geral do Processo, 6ª ed., São Paulo, Revista dos Tribunais, 1987, p. 280. 
fosse agravado pelo inevitável retardamento do remédio jurisdicional (periculum in mora).

\section{Importância das medidas cautelares}

As medidas cautelares, em razão da efetividade e imediatidade com que são concedidas para afastar a figura da lesão eventual, constituem tutela jurisdicional de elevado alcance social. A expressividade almejada pelo mens legislatori foi preponderante nessa modalidade de tutela, já que, confiando na técnica e sensibilidade do juiz, o estado delegou a este profissional o poder-dever de reprimir, de forma imediata, o dano jurídico. Há situações prementes, como por exemplo, o arbitramento dos alimentos provisionais, em que a urgência é necessária, mesmo com o risco de determinar a prestação de alimentos a quem não seja obrigado a esse dever. É indiscutível que se trata de medida de risco, em que o juiz decide com fundamento no princípio da razoabilidade do direito invocado. ${ }^{6}$ Cândido Rangel Dinamarco ${ }^{7}$ pontifica que, "o fumus boni juris expressa a probabilidade razoável e suficiente, que ao juiz compete medir em cada caso. Evitará quanto possível as cautelas constritivas que discrepem do direito substancial, mas preferirá errar concedendo as cautelas do que errar negando-as: em situação de risco, equilibrados, é preferivel optar por soluções que não deixem o direito material sujeito a sacrifícios".

Portanto, na medida em que a tutela cautelar afasta a situação de perigo de dano eventual e iminente, com fundamento na probabilidade da sua ocorrência, cria uma situação de risco com perspectiva do surgimento de um novo dano. Afinal, o periculum in mora e o fumus boni juris são pressupostos subjetivos da ação cautelar, que deverão ser analisados pelo juiz com acentuado espírito de moderabilidade.

\footnotetext{
6 Sem se esquecer, segundo a lição de Luiz Guilherme Marinoni, em sua obra Novas Linhas do Processo Civil, p. 157, que "a legitimação do exercício da jurisdição, depende da efetividade do contraditório."

7 Cândido Rangel Dinamarco, A Instrumentalidade..., op. cit., p. 260.
}

R. Fac. Direito, Curitiba, a.28, n.28, 1994/95, p.173-188 


\section{Atos e poder do juiz no processo}

O Estado, ao conceder ao juiz o poder de cautela, pretendeu assegurar que o potencial de dano, inserto na medida requerida, seja prontamente repelido pela autoridade judiciária, com a finalidade de evitar a ocorrência da lesão e assegurar a efetividade do direito.

Na executividade da decisão judicial, o Estado teve como escopo facultar ao juiz o poder-dever de afastar, de imediato, a previsão de danos em vias de se concretizar pela ação do lesionador. Afinal, no dizer de Pontes de Miranda ${ }^{8}$ "toda pretensão tem por fim a satisfação. Ela é somente meio; a satisfação é fim. Se não se exerce, como que dorme. A lei fixa prazos, ditos de prescrição, em que esse sono se faz parálise.

A regra é que cada pretensão possa corresponder ação, se os pressupostos para essa nascer ocorrer; mas casos há em que a pretensão fica sem ação.

Na realidade, trata-se, na expressão de Cappelletti (Giudici Legislatori?, esp. n. 4, p.13), citado por Cândido Rangel Dinamarco, ${ }^{9}$ de um poder capaz de restabelecer a normalidade das relações rompidas entre as partes ou seja, um equilibrio estável entre o imperativo axiológico e a segurança jurídica.

Para atingir esse desiderato o Estado concedeu ao magistrado o livre convencimento acerca da matéria sub examinis, assegurando à autoridade judicante a ampla e democrática análise dos fatos que ensejaram o acionamento da máquina jurisdicional.

Todavia, esse poder-dever não pode ser arbitrário ou alheio aos fatos que justificaram a concessão da medida cautelar. Nesse particular, Marcus Vinicius de Abreu Sampaio ${ }^{10}$ pontifica, com acerto, que "esse poder-dever, entretanto, quando extrapola os limites da atividade específica do juiz, ditada pelos artigos 125-132 - exceção feita ao artigo 131- e adentra o

8 Pontes de Miranda, Tratado das Ações, $5^{\circledR}$ ed., São Pualo, Revista dos Tribunais, 1970, p. 170 .

9 Cândido Rangel Dinamarco, A Instrumentalidade..., op. cit., p. 198.

10 Marcus Vinicius de Abreu Sampaio, O Poder Geral de Cautela do Juiz, São Paulo. Revista dos Tribunais, 1993, p. 139. 
campo da atividade cautelar disposta pelos já citados artigos 798 e 799 , assume contornos bastante diversos. Ou seja, quando o juiz atua com base no poder geral de cautela, não está ele a exercer um poder meramente jurisdicional onde pratica o ato mediante o processo exclusivamente interpretativo da norma e dentro dos seus estreitos limites. Quando age com base nos artigos 798 e 799 o juiz exerce a função jurisdicional bem como discricionária. "Na realidade, o poder discricionário do juiz tem como premissa maior facultar que a prestação da tutela jurisdicional afaste a ocorrência de um dano imediato, que possa resultar em lesão de difícil ou impossível reparação. A discricionariedade do magistrado tem sido questionada pelos doutrinadores, ocorrendo divergências nesse particular. ${ }^{.}$

Marcus Vinicius de Abreu Sampaio, ${ }^{12}$ citando Hely Lopes Meirelles, preleciona com acerto que "convém esclarecer que poder discricionário não se confunde com poder arbitrário. Discricionariedade e arbítrio são atitudes inteiramente diversas. Discricionariedade é liberdade de ação administrativa, dentro dos limites permitidos em lei; arbítrio é ação contrária ou excedente da lei. Ato discricionário, quando autorizado pelo direito, é legal e válido; ato arbitrário é sempre ilegítimo e inválido..."

É indiscutível que, o juiz deverá agir com discricionariedade, quando se trata de determinar medida provisória que julgar necessária na defesa da jurisdição, ou para evitar que uma parte possa causar a outra lesão grave ou de difícil reparação. ${ }^{13}$

11 Marcus Vinicius de Abreu Sampaio, O poder..., op. cit., p. 107, prescreve nesse sentido que, "muitos são os autores que negam o poder discricionário ao juiz, no exercício de sua atividade típica, até mesmo naqueles casos em que o magistrado tem que "interpretar" conceitos vagos ou indeterminados, a fim de aplicar a norma."

12 Marcus Vinicius de Abreu Sampaio, O poder..., op. cit., p. 102.

13 O Min. Sálvio de Figueiredo, em decisão proferida perante o Egrégio Superior Tribunal de Justiça (In RSTJ 26/378, a Eitação encontra-se na página 384), proclama com acerto e profundidade: "a interpretação das leis não deve ser formal, mas sim, antes de tudo, real, humana, socialmente útil (...). Se o juiz não pode tomar liberdades inadmissíveis com a lei, julgando contra legem, pode e deve, por outro lado, optar pela interpretação que mais atenda às aspirações da Justiça e do bem comum".

R. Fac. Direito, Curitiba, a.28, n.28, 1994/95, p.173-188 


\section{Condição para concessão da medida cautelar}

A ação cautelar exige justo receio de dano iminente. Isto significa ser necessário o atendimento de condições de admissibilidade para a concessão da medida almejada pelo autor da ação. ${ }^{14}$ Ensina Marcus Vinicius de Abreu Sampaio ${ }^{15}$ que "além das três condições de admissibilidade da ação (tertium genus do processo), inerente às ações como um todo, a doutrina costuma entender que outras duas condições de admissibilidade pertencem às ações cautelares". Seriam condições específicas já que inerentes apenas às cautelares - denominadas fumus boni iuris e periculum in mora e que não se confundiriam com o interesse de agir, possibilidade jurídica do pedido e legitimidade das partes".

É fácil concluir que são necessários indícios veementes de um fundado receio de lesão grave de difícil reparação para justificar a tutela jurisdicional preventiva. Para José Frederico Marques ${ }^{16}$ "na conjugação do fumus boni iuris com o periculum in mora é que reside o pressuposto jurídico do processo cautelar".

Portanto, somente após verificar a existência real desses pressupostos, que justifiquem adequadamente a tutela invocada, é que competirá ao magistrado concedê-la, sob pena de faltar com a prestação da jurisdiçãosituação inadmissível no Estado de Direito.

\section{Concessão da medida cautelar ex officio pelo juiz}

No curso do processo poderão ocorrer situações em que seja indispensável a intervenção ex officio do juiz, necessária à consecução da efetiva prestação da jurisdição.

14 Para Marcus Vinicius de Abreu Sampaio, O poder..., op. cit., p. 160 "seriam condições específicas - já que inerente apenas às cautelares - denominadas fumus boni iuris e periculum in mora e que não se confundiriam coll o interesse de agir, possibilidade jurídica do pedido e legitimidade das partes."

15 Marcus Vinicius de Abreu Sampaio, O poder..., op. cit., p., 160.

16 José Frederico Marques, Manual de Direito Processual Civil, $5^{\text {a }}$ ed., São Paulo, Saraiva, 1976 , p. 334. 
Os artigos 125,130 e 131 do CPC concedem ao magistrado a independência necessária na condução do processo, e até mesmo o direito de converter o julgamento em diligência (In RT 593/169 - RISTF 140), conforme aliás, previsão contida nos artigos 557 e 560 do CPC.

Afinal, consoante com o entendimento do Egrégio Superior Tribunal de Justiça ${ }^{17}$ da livre apreciação da prova pelo juiz, é um dos pressupostos da função jurisdicional. Todavia, ao conceder a medida sem provocação da parte, se deste fato resultar em dano a um dos litigantes, poderá o juiz ser responsabilizado?

Segundo o entendimento de Marcus Vinicius de Abreu Sampaio ${ }^{18}$ "a questão da responsabilidade civil decorrente dos danos causados à parte adversa pela execução da medida cautelar, muda um pouco de figura quando o ato jurisdicional é praticado de ofício, com fundamento nos artigos 798 e 799 do CPC, bem como no poder geral de cautela. Nessa hipótese, temos para nós que o juiz não poderá arcar com os prejuizos derivados da providência cautelar, fornecida por ele de oficio." (Destaquei).

Nesta situação o magistrado atua com autonomia e liberdade na prática do ato processual, objetivando sempre salvaguardar o interesse público, das partes, a lei e a moralidade. ${ }^{19}$

É óbvio que a decisão do magistrado deverá ser fundamentada, sob pena de macular a previsão Constitucional contida no art. 93, IX da CF/88, bem como justificar adequadamente o exercício de seu poder discricionário. Para tanto, é indispensável a prova da necessária imediatidade da ação

17 Theotonio Negrão, ao discorrer sobre o artigo 131 do CPC, em seu livro Código de Processo Civil comentado, transcreve importante decisão do STJ in verbis "a livre apreciação da prova, desde que a decisão seja fundamentada, considerada a lei e os elementos existentes nos autos, é um dos cânonẹ do nosso sistema processual." (STJ-4 ${ }^{a}$ turma, REsp. 7.870-SP, rel. Min. Sálvio de Figueiredo, j. 03.12.91, deram provimento parcial, v.u., DJU 03.02.92, p. 469, $1^{\text {a }}$ col., em.).

18 Marcus Vinicius de Abreu Sampaio, O poder..., op. cit., p. 201.

19 Luiz Guilherme Marinoni, em sua obra Tutela Cautelar e Tutela Antecipatória, p. 131, nesse aspecto preleciona " $\mathrm{n} \mathbf{3}$ verdade, se concluímos que a execução da tutela sumária urgente não se subordina às regras próprias do processo de execução, constituindo uma forma de execução processual peculiar, somos obrigados a atribuir ao juiz da tutela urgente uma ampla latitude de poderes destinados à determinação das modalidades executivas."

R. Fac. Direito, Curitiba, a.28, n.28, 1994/95, p. 173-188 
estatal para evitar lesão na iminência de ocorrer, irreparável ou de difícil reparação.

Estando afastado o dolo ou a fraude (do magistrado), previstos no art. 133, inciso I do CPC, não haverá como responsabilizar o juiz que agiu de conformidade com a lei, e em circunstâncias que justifiquem a pronta e eficiente prestação da jurisdição - até mesmo sob pena de concorrer para a lesividade do direito da parte em virtude da sua omissão, face a previsão contida no art. 133, II do CPC.

Neste caso, pontifica José Frederico Marques, ${ }^{20}$ "se a providência cautelar puder enquadrar-se, razoavelmente, nos poderes instrumentais inerentes ao exercício da jurisdição (art. 125), facultado está ao juiz concedê-la de ofício."

A existência de uma situação extrema, urgente ou de perigo, indiscutivelmente possibilita ao magistrado o poder-dever de determinar procedimentos impeditivos da ocorrência da lesividade. ${ }^{21}$

O que se observa por conseguinte, é a existência de um direito prestes a ser lesado, e que exija uma pronta, imediata e eficaz ação do órgão estatal, para determinar a cessação do ato lesivo. Aliás, há dispositivos legais que uutorizam a concessão de medidas ex officio, como aqueles contidos nos inciso II, do art. $7^{\circ}$ da lei $\mathrm{N}^{\circ} 1.533 / 51$, e nos artigos 793 e 266 do CPC.

Segundo a lição de Sérgio Sahione Fadel, ${ }^{22}$ "o que impede considerar, é que verdadeiramente o dano exista ou esteja na iminência de ser praticado e o magistrado dele tenha conhecimento." Todavia, alguns doutrinadores, como J.J. Calmon de Passos, ${ }^{23}$ criticam o poder cautelar ex

20 José Frederico Marques, Manual..., op. cit., p. 355.

21 Luiz Guilherme Marinoni, em sua obra Efetividade do Processo e Tutela de Urgência, na página 79, ensina que, "a urgência, em alguns casos, pode exigir a efetivação de uma medida cautelar antes da ouvida do réu. Para a justificação de tais medidas alega-se, em geral, que a tutela dos direitos ameaçados por perigo de dano eminente e irreparável pode tornar necessárias medidas imediatas sem um completo esclarecimento da situação fática, e recorda-se, ainda, que a omissão da audiência prévia do réu pode ser ditada pelo objetivo de não colocar este último em condições det frustrar a eficácia da prática do próprio provimento (suspício de dilapidatione bonorum seu de fuga).

22 Sérgio Sahione Fadel, Código..., op. cit., p. 650.

23 J.J. Calmon de Passos, Comentários ao Código de Processo Civil. São Paulo, Revista dos Tribunais, 1984 , p. 91. 
officio do juiz, ao prelecionar "que se não cuida de atribuição, ao juiz, de poder para, ex officio, acautelar o interesse das partes". "Aqui ainda mais amplo seria o poder do juiz, em flagrante contradição com a dispositividade do processo de cognição ou de execução a que se vincularia o processo cautelar oficiosamente instaurado. Dessa vinculação do juiz à iniciativa do interessado, sem a qual não pode exercitar sua jurisdição, também resulta a não fungibilidade do pedido cautelar, visto como permitir ao magistrado decidir ultra, extra ou citra petita é negar o princípio dispositivo."

Todavia, ao determinar medida cautelar ex officio o juiz sempre atentará para a efetividade do processo, valendo-se da sua discricionariedade para defender a soberania do Estado "na sua mais elevada expressão, que é a administração da justiça", no dizer de Ovídio A. Baptista da Silva. ${ }^{24}$

Ora, de todos esses fatos, ilaciona-se que nos casos expressamente autorizados por lei poderá o magistrado conceder medidas ex officio. Isto significa que seu poder é limitado, e que no caso de inobservância desse requisito, o juiz poderá causar lesão à parte. No entanto, mesmo na ocorrência desse fato, o magistrado não poderá ser responsabilizado civilmente, já que a atividade jurisdicional envolve ponderáveis situações de riscoinerentes à própria atividade Estatal.

\section{Dano decorrente da concessão de medida cautelar}

A responsabilidade civil decorre do dano, atendidos ainda os pressupostos da culpa e do nexo causal. O conceito de dano é expresso de forma precisa por Eduardo A. Zanoni, ${ }^{25}$ que preleciona "desde una perspectiva objetiva, el daño se define como el menoscabo que, a consecuencia de un acaecimiento o evento determinado, sufre una persona,

24 Ovídio A. Baptista da Silva, Curso de Processo ('ivil, v.x, Porto Alegre, Sergio A. Fabris, 1993, p. 70.

25 Eduardo A. Zanoni, El daño en La responsabilidad Civil, $24^{\mathrm{a}}$ ed., Buenos Aires, Editoral Astrea, 1987, p. 70.p. 1.

R. Fac. Direito, Curitiba, a.28, n.28, 1994/95, p.173-188 
ya en suas bienes vitales naturales, ya en sua propriedad, ya en su patrimonio." ${ }^{26}$

Não resta dúvida que o escopo principal da medida cautelar consiste em evitar lesão de difícil reparação, e não provocar novo dano. O risco será inerente a esta situação fática, considerando a probabilidade dos fatos apresentados ao juiz para a concessão da medida cautelar. Todavia, é inquestionável que, ocorrendo uma determinação judicial que provoque maior dano do que o pretendido evitar, há outros recursos suscetíveis de cassar a ordem emanda da autoridade judicante. ${ }^{27}$ Mesmo se considerarmos a precaução do magistrado na concessão da medida cautelar, ela poderá resultar em dano à parte. Nesse caso, existem vias recursais que possibilitam a suspensão dessa medida, e.g. o mandado de segurança. Trata-se de uma situação de absoluta excepcionalidade, em face da possibilidade do próprio juiz em revogá-la ou modificá-la de imediato, conforme previsão contida no art. 807 do CPC. Outrossim, o poder de cautela do juiz, nos casos apontados, é restrito àquelas situações previstas nos artigos 588, 1797, 888, 1018,1001 do CPC. Dessa forma, não se deve confundir a concessão de medida cautelar inaudita altera parte, onde o juiz defere liminar sem a audiência prévia da parte contrária, com a medida cautelar ex officio.

Portanto, será realmente impossível responsabilizar o magistrado em virtude da concessão de medida ex officio, porque nesse caso o mesmo praticará atos na defesa da jurisdição.

Silva, ${ }^{28}$ para a decretação de medidas cautelares destinadas a salvaguardar
paratista da

Para Calmon de Passos, em sua obra citada, p. 108, "o dano jurídico, reclama, para sua configuração, em primeiro lugar, uma diminuição direta ou indireta do patrimônio de alguém, imputável a outrem, ou por força da lei, ou como decorrência dos fatos ou em razão de um contrato, que por ela deve responder também patrimonialmente, pelo que aquela diminuição do patrimônio do lesado deve ser suscetível de avaliação ou estimativa pecuniária."

27 Theotonio Negrão, em seu Código de Processo Civil comentado, ao tecer considerações sobre o art. 798 do CPC, destaca, "cabe mandado de ségurança contra decisão que, sem audiência do réu, concede liminarmente medida cautelar inominada, com fundamento em circunstância de fato que não foi inequivocamente demostrada desde logo. (RT 598/190)."

28 Ovídio A. Baptista da Silva, Curso..., op. cit., p. 70. 
o imperiu iudicis, dão lugar às medidas cautelares ex officio, pois, em tais casos, como o próprio Calamandrei reconhece, não se trata de defender direito das partes, quando a decretação das medidas cautelares haveria de ficar na dependência de requerimento da parte interessada, e sim de armar o magistrado de poderes que lhe possibilitem, a defesa da jurisdição."

O dano decorrente das medidas jurisdicionais determinadas pelo magistrado, nessas situações, deve ser suportado pela parte lesada, em face da ausência do elemento culpa e nexo causal. E importante ressalvar os casos de dolo ou fraude (art. 133 do CPC), que envolvem responsabilidade do magistrado.

\section{Responsabilidade civil do magistrado}

A prática de ato processual pelo magistrado, capaz de gerar lesão ao interesse de uma das partes, para que possa ser atribuída ao juiz deverá vir configurada com os elementos que tipificam a responsabilidade civil, ou seja, dolo ou fraude na forma expressamente prevista no art. 133 do CPC.

As disposições previstas no artigo 811 do CPC referem-se apenas e exclusivamente ao direito do prejudicado pela medida cautelar infundada ou frustrada, não fazendo referência ao magistrado. ${ }^{29}$

$\mathrm{Na}$ realidade, a atividade ex officio realizada pelo juiz tem como pressuposto reprimir a atuação da parte que esteja agindo em desconformidade com a lei e a justiça. ${ }^{30}$

Carlos Aurélio Mota de Souza ${ }^{31}$ ensina que há casos em que o juiz, por sua iniciativa exclusiva, que aliás se enquadra no seu poder-dever de

29 Humberto Theodoro Junior, em sua obra Curso de Direito Processual Civil, p. 432 tipifica este fato ensinando que, "a responsabilidade civil, na espécie, é puramente objetiva, de sorte que seus fundamentos são apenas a lesão do requerido, a frustração da medida cautelar nos termos do art. 811 e nexo causal entre a medida e o dano."

30 Ovídio A. Baptista da Silva, em sua obra citada, p. 70 ensina com clareza, "quer dizer, em última análise, passa-se a reconhecer ao magistrado poderes para defender a soberania do Estado, na sua mais elevada expressão, que é a da administração da justiça desde, porém, que os particulares envolvidos no litígio, nisso tenham interesse e obriguem o representante do Estado a defender-se...!."

R. Fac. Direito, Curitiba, a.28, n.28, 1994/95, p. 173-188 
determinar providência de ofício, objetivando salvaguardar a integridade da justiça. Nesse sentido pontifica que, "assim como o juiz, ao tomar conhecimento (pela verdade sabida) de delito praticado pelas partes (ex. falso testemunho), deve ordenar investigação criminal (art. 40 do CPP), por igual princípio pode apreciar atos abusivos contra a administração da justiça (poderes administrativos que lhe foram conferidos pelo art. 125, II e III), declarando, de oficio, a litigância de má-fé, tipificando os limites da responsabilidade (o an debeatur)".

Portanto, somente a fraude e o dolo autorizam a responsabilidade do juiz na prática de ato processual.

Aliás, se todos os magistrados, na prática de atos processuais considerados como de defesa da jurisdição fossem civilmente responsabilizados, a estabilidade da sociedade estaria seriamente comprometida - já que os magistrados não praticariam ou hesitariam em praticar os referidos atos, destinados a salvaguardar os interesses da sociedade.

Por outro lado, todos os atos processuais realizados pelo magistrado são suscetíveis de recursos previstos na lei processual, e até da correição parcial ou representação junto à Corregedoria da Justiça. Isto significa que se houve abuso de direito por parte do magistrado, há inúmeros recursos capazes de impedir a ação lesiva resultante do ato processual determinado de oficio pelo magistrado.

Para tanto, há limites legais para a ação do magistrado. Afinal, como afirmamos, o poder-dever do magistrado não é ilimitado, e o seu poder discricionário não poderá ser confundido com o poder arbitrário. ${ }^{32}$

Nesse particular, Ovídio A. Baptista da Silva ${ }^{33}$ esclarece que, "finalmente, deve-se observar que as medidas cautelares ex officio não foram criadas pelo Código de Processo Civil, que se limita, no art. 797, apenas a

31 Carlos Aurélio Mota de Souza, Poderes Éticos do Juiz, Porto Alegre, Sergio A. Fabris, 1987 , p. 107.

32 Ovídio A. Baptista da Silva, em sua obra citada, p. 73, preleciona com objetividade e acerto que, "é necessário, porém, advertir que o poder que o magistrado possa ter para defender a jurisdição, não se confunde com o direito da parte. Uma coisa é poder do Estado (Chiovenda), outra ação (direito da parte)."

Ovídio A. Baptista da Silva, Curso.... op. cit., p. 73 
restringir-lhe o emprego, proibindo que o juiz delas se valha a não ser nos casos excepcionais previstos em lei."

\section{Conclusões}

O poder de cautela ex officio é uma forma de possibilitar ao juiz a adoção de comandos processuais destinados a salvaguardar os interesses da administração da justiça, na sua mais elevada expressão. Calmon de Pas$\operatorname{sos}^{34}$ preleciona que, "permite a lei que o juiz autorize a prática de determinados atos." E, adiante conclui, "mas esse poder de autorização deferido ao juiz não é arbitrário nem mesmo discricionário. Ele cessa ante os obstáculos postos pela lei, ou melhor dizendo, postos pela própria ordem jurídica em que o juiz atua. Nem tudo pode o magistrado autorizar, mesmo quando prejuízo decorra para o resultado útil do processo."

A moderna doutrina processual vem admitindo a ampliação dos poderes conferidos ao magistrado, ${ }^{35}$ como forma de tornar mais efetivo o desenvolvimento do processo bem como o seu resultado. Ovídio Baptista ${ }^{36}$ entende que, "é perfeitamente compreensível, portanto, que o magistrado, ao utilizar-se destes poderes, decretando medidas com tal finalidade, não dependa de requerimento das partes."

Isto significa que o juiz apenas previne, evitando a ocorrência de fatos lesivos que possam resultar em danos ao interesse das partes e do próprio Estado. Mesmo assim haverá restritividade nesse poder-dever do magistrado, como é o caso das medidas cautelares concedidas inaudita altera parte, que circunscrevem-se à lei e ao prudente arbítrio do juiz.

Ovídio Baptista, ${ }^{37}$ nesse sentido, preleciona que, "entre nós, ao contrário, as medidas cautelares ex officio, decretáveis para defesa da

34 J.J. Calmon de Passos, Comentários..., op. cit., p. 115.

35 Carlos Aurélio Mota de Souza, na sua obra Poderes Éticos do Juiz, p. 105, filia-se ao entendimento de que, "nesta área, entendemos que o juiz deve ampliar seus poderes para declarar, de oficio, até onde possa, como contrária à lei processual e à administração da justiça, toda conduta prejudicial à igualdade das partes e ao rápido e regular andamento da causa."

36 Ovídio A. Baptista da Silva, Curso..., op. cit., p. 70.

R. Fac. Direito, Curitiba, a.28, n.28, 1994/95, p.173-188 
soberania do Estado e da dignidade da justiça , como propunha Calamandrei, somente podem ser aplicadas "em casos excepcionais", quando "expressamente autorizados por lei". ${ }^{38} \mathrm{O}$ juiz não poderá, assim, ser responsabilizado pelos atos praticados na defesa dos maiores interesses da justiça e do Estado, quando agir em conformidade com as exigências particulares do caso, segundo o prudente arbítrio do juízo. Todavia, se o juiz extrapolar no seu poder-dever, agindo em desacordo com os comandos legais, poderá ser responsabilizado se do fato resultar dano a qualquer das partes.

Neste caso, a responsabilidade será objetiva (art. 15 do CCB e art. 37, IX da $\mathrm{CF} / 88$ ), cabendo nesse caso ação contra o Estado.

Todavia, quando se trata de medida decretada pelo juiz, e que tenha sido provocado pela parte, a responsabilidade civil será de quem agiu ilegalmente. É que, nesta situação "não sendo ele quem provocou a tutela jurisdicional, ensina Marcus Vinicius de Abreu Sampaio, ${ }^{39}$ também não se the pode atribuir responsabilidade pelo resultado desse ato, que repita-se, não dera ensejo."

Por conseqüência, o magistrado jamais poderá ser responsabilizado por ato a que deu causa em decorrência de provocação da parte, ou então, quando agiu estritamente nos parâmetros da lei para evitar lesão iminente de difícil reparação ${ }^{40}$ ou em defesa da jurisdição.

$\mathrm{O}$ ato ex officio do juiz sempre será destinado a assegurar a eficiente e pronta intervenção da justiça, repelindo a eventualidade de lesão e assegurando às partes o estado de direito. Somente dessa forma, e mediante a

37 Ovídio A. Baptista da Silva, Curso.... op. cit., p.70.

38 Humberto Theodoro Junior, Curso..., op. cit., p. 393, ensina nesse aspecto "... já que tem nada que ver com os casos de medidas cautelares ex officio, ou seja, aquelas que a lei, em casos excepcionais e mediante texto expresso, permite que o juiz tome até mesmo sem requerimento da parte (art. 797). Essas são, por sua própria natureza, diligências integrantes do procedimento principal, como simples incidentes."

39 Marcus Vinicius de Abreu Sampaio, O poder..., op. cit., p. 201.

40 Para Marcus Vinicius de Abreu Sampaio, O poder... op. cit., p. 201, "a questão da responsabilidade civil decorrente dos danos causados à parte adversa pela execução da medida cautelar, muda um pouco de figura, quando o ato jurisdicional é praticado de ofício, com fundamento nos artigos 798 e 799 do CPC, bem como no poder geral de cautela. Nessa hipótese, temos para nós que o juiz não poderá arcar com os prejuizos derivados da providência cautelar, fornecida por ele de oficio." 
pronta e eficaz intervenção do juiz, a justiça possibilitará o equilíbrio social e a efetividade do processo, consistente no justo e perfeito equacionamento do litígio.

Finalmente, ao utilizar-se do poder discricionário o juiz deve estar consciente da grave responsabilidade que pesam sobre seus ombros isto porque, no dizer de Humberto Theodoro Junior, ${ }^{41}$ "no exercício desse imenso e indeterminado poder de ordenar as "medidas que julgar adequadas", para evitar o dano à parte, provocado ou ameaçado pelo adversário, a discrição do juiz assume proporções quase absolutas. Estamos em presença de autêntica norma em branco, que confere ao magistrado dentro do estado de direito, um poder puro, idêntico ao do pretor romano, quando no exercício do imperium, decreta o interdicta". E, adiante conclui, "esses poderes absolutos, obviamente, nenhum órgão estatal os detém, no moderno Estado Democrático de Direito."

Cabe ao magistrado, através do seu tirocínio, sensibilidade e técnica jurídica, decidir a questão com sabedoria e serenidade para atingir o primado da justiça, e poder repousar o sono dos justos.

\section{Referências bibliográficas}

CINTRA, Antonio Carlos de Araújo; GRINOVER, Ada Pellegrini; DINAMARCO, Cândido Rangel. Teoria Geral do Processo. $6^{a}$ ed. São Paulo: Editora Revista dos Tribunais, 1987.

DINAMARCO, Cândido Rangel. A Instrumentalidade do Processo. $3^{\text {a }}$ ed. São Paulo: Ed. Revista dos Tribunais. Malheiros Editora Ltda, 1990.

FADEL, Sergio Sahione. Código de Processo Civil Comentado. $4^{\mathrm{a}}$ ed. Rio de Janeiro: Ed. Forense S/A, 1982.

MARINONI, Luiz Guilherme. Tutela Cautelar e Tutela Antecipatória. São Paulo: Ed. Revista dos Tribunais, 1992.

. Novas Linhas do Processo Civil. São Paulo: Ed. Revista dos Tribunais, 1993.

Efetividade do Processo e Tutela de Urgência. Porto Alegre: Sergio Antonio Fabris Editor, 1994.

MARQUES, José Frederico. Manual de Processo Civil. $5^{2}$ ed. São Paulo: Ed. Saraiva, 1976. MIRANDA, Pontes de. Tratado das ações. São Paulo: Ed. Revista dos Tribunais, 1970.

41 Humberto Theodoro Junior, Curso..., op. cit., p. 77.

R. Fac. Direito, Curitiba, a.28, n.28, 1994/95, p. 173-188 
NEGRÃO, Theotonio. Código de Processo Civil. $24^{2}$ ed. São Paulo: Malheiros Editores Ltda, 1993.

PASSOS, J.J. Calmon de. Comentários ao Código de Processo Civil. vol. X. São Paulo: Ed. Revista dos Tribunais, 1984.

SAMPAIO, Marcus Vinicius de Abreu. O Poder Geral da Cautela do juiz. São Paulo: Ed. Revista dos Tribunais, 1993.

SILVA, Ovídio Baptista da. Curso de Processo Civil. vol. III. Porto Alegre: Sérgio Antonio Fabris Editor, 1993.

SOUZA, Carlos Aurélio Mota de. Poderes Éticos do Juiz. Porto Alegre: Sérgio Antonio Fabris Editor, 1987.

THEODORO JUNIOR, Humberto. Curso de Direito Processual Civil. vol. III. $12^{\mathbf{a}}$ ed. Rio de Janeiro: Ed. Forense S.A., 1994.

Tutela Cautelar - Direito Processual ao Vivo. Rio de Janeiro: Ainde Ed., 1992.

ZANONI, Eduardo A. El Daño em La Responsabilidad Civil. 24ª ed. Buenos Aires: Editorial Ástrea, 1987. 